\title{
Influenza vaccination might reduce the risk of ischemic stroke in patients with atrial fibrillation: A population-based cohort study
}

\author{
Pai-Feng Kao ${ }^{1,6, *}$, Ju-Chi Liu ${ }^{1,6, *}$, Yi-Ping Hsu ${ }^{1}$, Li-Chin Sung ${ }^{1,6}$, Tsung-Yeh Yang ${ }^{1}$, \\ Wen-Rui Hao ${ }^{1}$, Ying-Chin Lin ${ }^{2,3}$ and Szu-Yuan Wu ${ }^{4,5,6,7}$ \\ ${ }^{1}$ Division of Cardiovascular Medicine, Department of Internal Medicine, Shuang Ho Hospital, Taipei Medical University, New \\ Taipei City, Taiwan \\ ${ }^{2}$ Department of Family Medicine, Shung Ho Hospital, Taipei Medical University, New Taipei, Taiwan \\ ${ }^{3}$ Department of Family Medicine, School of Medicine, College of Medicine, Taipei Medical University, Taipei, Taiwan \\ ${ }^{4}$ Institute of Toxicology, College of Medicine, National Taiwan University, Taipei, Taiwan \\ ${ }^{5}$ Department of Radiation Oncology, Wan Fang Hospital, Taipei Medical University, Taipei, Taiwan \\ ${ }^{6}$ Department of Internal Medicine, School of Medicine, College of Medicine, Taipei Medical University, Taipei, Taiwan \\ ${ }^{7}$ Department of Biotechnology, Hungkuang University, Taichung, Taiwan \\ *These authors have contributed equally to this work \\ Correspondence to: SzU-Yuan Wu, email: szuyuanwu5399@gmail.com \\ Keywords: influenza vaccination; atrial fibrillation; ischemic stroke \\ Received: June 11,2017 Accepted: July 26, $2017 \quad$ Published: November 09, 2017 \\ Copyright: Kao et al. This is an open-access article distributed under the terms of the Creative Commons Attribution License 3.0 \\ (CC BY 3.0), which permits unrestricted use, distribution, and reproduction in any medium, provided the original author and source \\ are credited.
}

\section{ABSTRACT}

Purpose: Atrial fibrillation (AF) is associated with the risk of ischemic stroke, regardless of the administration of appropriate antithrombotic prophylaxis. This study investigated whether influenza vaccination is associated with the risk of ischemic stroke, to determine a solution to reduce this risk in patients with AF.

Methods: We used data from the Taiwan National Health Insurance Research Database. The study cohort comprised all patients diagnosed as having AF ( $n=14$ 454) before January 1, 2005; these patients were followed until December 31, 2012. The index date was January 1, 2005. A propensity score was derived using a logistic regression model to estimate the effect of vaccination by accounting for covariates that predict receiving the intervention (vaccine). A Cox proportional hazard model was used to calculate the hazard ratios (HRs) of ischemic stroke in vaccinated and unvaccinated patients with AF.

Results: We included 6570 patients (2547 [38.77\%] with and 4023 [61.23\%] without influenza vaccination). The adjusted HRs (aHRs) of ischemic stroke were lower in the vaccinated patients than in the unvaccinated patients (influenza season, noninfluenza season, and all seasons: aHRs $=0.59,0.50$, and $0.55 ; P<0.001, P<$ 0.001 , and $P<0.001$, respectively).

Conclusions: Influenza vaccination might exert a dose-response effect against ischemic stroke in patients with AF who have risk factors for ischemic stroke by reducing the incidence of ischemic stroke, particularly in those aged 65-74 and $\geq 75 \mathrm{y}$. 


\section{INTRODUCTION}

Ischemic stroke may be a presenting manifestation of atrial fibrillation (AF) in some patients and may occur in some patients despite the administration of appropriate antithrombotic prophylaxis [1-3]. Compared with emboli from carotid disease, AF has been strongly associated with more severe ischemic stroke and relatively longterm transient ischemic attack, presumably because of embolization of large particles in $\mathrm{AF}[4,5]$. Moreover, $\mathrm{AF}$ is associated with particularly severe ischemic stroke mostly caused by relatively large emboli from the left atrial appendage [6].

The efficacy of antithrombotic therapy in preventing recurrent stroke in patients with $\mathrm{AF}$ and ischemic stroke has been extensively reported [7-10]. Anticoagulant therapy effectively reduced the risk of systemic embolization in patients with AF [10]. However, anticoagulant therapy may increase the risk of major bleeding [11]. The CHADS2 score is a clinical prediction rule for estimating stroke risk in patients with $\mathrm{AF}$, a common and severe form of congestive heart failure associated with ischemic stroke [12]. This score is used to determine whether patients should receive anticoagulation or antiplatelet therapy, because AF can cause blood stasis in the upper heart chambers, leading to the formation of a mural thrombus that can dislodge into blood flow, reach the brain, interrupt the blood supply to the brain, and cause stroke [12]. Because the risk of major bleeding is increased in most patients receiving anticoagulants, careful consideration of the risk-to-benefit ratio is necessary.

An alternative treatment can be beneficial for patients with AF having a risk of ischemic stroke and can reduce the risk of major bleeding in patients receiving anticoagulants. Lavallee et al. and Nichol et al. have suggested that influenza vaccination in elderly patients aged 60-65 y prevents brain infarction by reducing infections [13, 14]. Taken together, these findings indicate that $\mathrm{AF}$ is associated with a high risk of ischemic stroke, regardless of the administration of appropriate antithrombotic prophylaxis, and that anticoagulant use increases the risk of major bleeding in most patients with AF.

Influenza infection can activate systemic inflammatory responses and increase the sympathetic tone that plays a crucial role in the pathogenesis of AF $[15,16]$. In Taiwan, influenza infection was significantly associated with the development of AF and significantly increased the risk of AF, which could be reduced through influenza vaccination [17]. Theoretically, reducing AF risk or administering influenza vaccine might reduce the risk of ischemic stroke. The current study investigated the association of influenza vaccination with the risk of ischemic stroke to determine a solution to reduce the risk of ischemic stroke in patients with AF.

\section{RESULTS}

The study cohort consisted of 6570 patients, of whom 2547 (38.77\%) and 4023 (61.23\%) received and did not receive influenza vaccination, respectively (Table 1). The total follow-up durations of the unvaccinated and vaccinated patients were 12291.9 and 14810.0 person-y, respectively. The prevalence of preexisting medical comorbidities, namely dyslipidemia $(P=0.003)$, vascular disease $(P<0.001)$, pneumonia $(P<0.001)$, and dialysis $(P=0.009)$, was higher in the unvaccinated patients than in the vaccinated patients. By contrast, the prevalence of congestive heart failure $(P<0.001)$ was higher in the vaccinated patients than in the unvaccinated patients. In addition, the distribution of age, monthly income, urbanization level, and drug use significantly differed between the vaccinated and unvaccinated patients (Table 1). A higher proportion of the vaccinated patients used warfarin, statin, metformin, ACEI, and aspirin for $>28$ cDDDs [18]. A lower proportion of the vaccinated patients had a monthly income of $\geq \mathrm{NT} \$ 33,301$ and resided in urban areas. Table 2 presents the risk of ischemic stroke observed in the unvaccinated and vaccinated patients. We calculated PSs after adjusting for age, sex, CCI, comorbidities, urbanization level, and monthly income. The adjusted HRs (aHRs) of ischemic stroke were lower in the vaccinated patients than in the unvaccinated patients (influenza season, noninfluenza season, and all seasons: aHRs $=0.59,0.50$, and $0.55 ; P<0.001, P<0.001$, and $P$ $<0.001$, respectively). The stratified analysis revealed that the aHRs remained significantly lower in the vaccinated patients, particularly in those aged $65-74$ and $\geq 75 \mathrm{y}$, regardless of sex. The aHRs of ischemic stroke were lower in the vaccinated patients than in the unvaccinated patients during all seasons (aged 55-64, 65-74, and $\geq 75 \mathrm{y}$ : aHRs $=$ $0.69,0.48$, and $0.45 ; P<0.05, P<0.001$, and $P<0.001$, respectively). During the influenza or noninfluenza season, the aHRs decreased regardless of age or sex, except in the 55-64-y-old age group, which had a relatively smaller sample size compared with the other subgroups (Table 2). Notably, despite the small sample size of this age group, the aHRs remained significantly lower in the vaccinated patients during the noninfluenza season. The stratified analysis indicated that the aHRs were significantly lower in the vaccinated patients, irrespective of sex, age, or season. The aHRs of ischemic stroke were lower in the vaccinated patients than in the unvaccinated patients during all seasons (women and men: aHRs $=0.51$ and $0.61 ; P<0.001$ and $P<0.001$, respectively). The aHRs remained significantly lower in the vaccinated patients during the influenza season, particularly in the women. Moreover, the aHRs were significantly lower in the vaccinated men during the noninfluenza season.

In the sensitivity analysis, adjustments were made to examine the association of age, sex, CCI, comorbidities, 
Table 1: Characteristics of the sample population

\begin{tabular}{|c|c|c|c|c|c|c|c|}
\hline & \multicolumn{2}{|c|}{ Whole cohort $(\mathrm{n}=\mathbf{6 5 7 0})$} & \multicolumn{2}{|c|}{ Unvaccinated patients $(n=4023)$} & \multicolumn{2}{|c|}{ Vaccinated patients $(n=2547)$} & \multirow{2}{*}{$P^{a}$} \\
\hline & $\mathbf{n}$ & $\%$ & $\mathbf{n}$ & $\%$ & $\mathbf{n}$ & $\%$ & \\
\hline Age, y $($ Mean \pm SD) & \multicolumn{2}{|c|}{$73.39(9.65)$} & \multicolumn{2}{|c|}{$72.79(10.68)$} & \multicolumn{2}{|c|}{$74.33(7.67)$} & $<0.001$ \\
\hline $55-64$ & 1502 & 22.86 & 1188 & 29.53 & 314 & 12.33 & \\
\hline $65-74$ & 2111 & 32.13 & 1059 & 26.32 & 1052 & 41.30 & $<0.001$ \\
\hline$\geq 75$ & 2957 & 45.01 & 1776 & 44.15 & 1181 & 46.37 & \\
\hline \multicolumn{8}{|l|}{ Sex } \\
\hline Women & 3100 & 47.18 & 1913 & 47.55 & 1187 & 46.60 & \multirow{2}{*}{0.453} \\
\hline Men & 3470 & 52.82 & 2110 & 52.45 & 1360 & 53.40 & \\
\hline \multicolumn{8}{|l|}{$\mathrm{CCI}$} \\
\hline 0 & 1004 & 15.28 & 596 & 14.81 & 408 & 16.02 & \multirow{4}{*}{0.007} \\
\hline 1 & 1346 & 20.49 & 812 & 20.18 & 534 & 20.97 & \\
\hline 2 & 1386 & 21.10 & 814 & 20.23 & 572 & 22.46 & \\
\hline$\geq 3$ & 2834 & 43.14 & 1801 & 44.77 & 1033 & 40.56 & \\
\hline \multicolumn{8}{|l|}{ Comorbidities } \\
\hline Diabetes & 2244 & 34.16 & 1408 & 35.00 & 836 & 32.82 & 0.070 \\
\hline Hypertension & 4922 & 74.92 & 2983 & 74.15 & 1939 & 76.13 & 0.071 \\
\hline Dyslipidemia & 2550 & 38.81 & 1618 & 40.22 & 932 & 36.59 & 0.003 \\
\hline Congestive heart failure & 3108 & 47.31 & 1810 & 44.99 & 1298 & 50.96 & $<0.001$ \\
\hline Vascular disease & 1010 & 15.37 & 686 & 17.05 & 324 & 12.72 & $<0.001$ \\
\hline Pneumonia & 1436 & 21.86 & 971 & 24.14 & 465 & 18.26 & $<0.001$ \\
\hline Dialysis & 452 & 6.88 & 303 & 7.53 & 149 & 5.85 & 0.009 \\
\hline \multicolumn{8}{|l|}{ Warfarin } \\
\hline$<28 \mathrm{cDDD}$ & 5113 & 77.82 & 3225 & 80.16 & 1888 & 74.13 & \multirow{2}{*}{$<0.001$} \\
\hline$\geq 28 \mathrm{cDDD}$ & 1457 & 22.18 & 798 & 19.84 & 659 & 25.87 & \\
\hline \multicolumn{8}{|l|}{ Aspirin } \\
\hline$<28$ cDDD & 2422 & 36.86 & 1698 & 42.21 & 724 & 28.43 & \multirow{2}{*}{$<0.001$} \\
\hline$\geq 28 \mathrm{cDDD}$ & 4148 & 63.14 & 2325 & 57.79 & 1823 & 71.57 & \\
\hline \multicolumn{8}{|l|}{ Statin } \\
\hline$<28 \mathrm{cDDD}$ & 4775 & 72.68 & 3040 & 75.57 & 1735 & 68.12 & \multirow{2}{*}{$<0.001$} \\
\hline$\geq 28 \mathrm{cDDD}$ & 1795 & 27.32 & 983 & 24.43 & 812 & 31.88 & \\
\hline \multicolumn{8}{|l|}{ ACEI } \\
\hline$<28$ cDDD & 2163 & 32.92 & 1580 & 39.27 & 583 & 22.89 & \multirow{2}{*}{$<0.001$} \\
\hline$\geq 28 \mathrm{cDDD}$ & 4407 & 67.08 & 2443 & 60.73 & 1964 & 77.11 & \\
\hline \multicolumn{8}{|l|}{ Metformin } \\
\hline$<28 \mathrm{cDDD}$ & 5249 & 79.89 & 3292 & 81.83 & 1957 & 76.84 & \multirow{2}{*}{$<0.001$} \\
\hline$\geq 28 \mathrm{cDDD}$ & 1321 & 20.11 & 731 & 18.17 & 590 & 23.16 & \\
\hline Urbanization level & & & & & & & \\
\hline Urban & 4287 & 65.25 & 2736 & 68.01 & 1551 & 60.90 & \\
\hline Suburban & 1546 & 23.53 & 893 & 22.20 & 653 & 25.64 & $<0.001$ \\
\hline Rural & 737 & 11.22 & 394 & 9.79 & 343 & 13.47 & \\
\hline Monthly income (NT\$) & & & & & & & \\
\hline 0 & 840 & 12.79 & 509 & 12.65 & 331 & 13.00 & \\
\hline $1-21000$ & 1704 & 25.94 & 936 & 23.27 & 768 & 30.15 & \\
\hline $21000-33300$ & 2535 & 38.58 & 1495 & 37.16 & 1040 & 40.83 & $<.001$ \\
\hline$\geq 33301$ & 1491 & 22.69 & 1083 & 26.92 & 408 & 16.02 & \\
\hline
\end{tabular}

${ }^{\mathrm{a}}$ Comparison between the unvaccinated and vaccinated patients

Vascular disease (e.g., peripheral artery disease, myocardial infarction, or aortic plaque) 
urbanization level, monthly income, and drug use with the incidence of ischemic stroke in different models. As presented in Table 3, the effects of vaccination remained significant in the subgroups of various covariates during the influenza season. Vaccination dose-dependently reduced the risk of ischemic stroke in all the subgroups and the main model with additional covariates (warfarin, statin, metformin, ACEI, or aspirin use). All the aHRs indicated that vaccination significantly reduced the risk of ischemic stroke in all the subgroups, regardless of comorbidities or drug use $(P<0.001)$. Our data revealed that the vaccination frequency reflected a protective effect against ischemic stroke during the influenza season. The protective effect was more predominant in the patients aged $\geq 75$ y ( 1 vaccination: aHR $=0.71,95 \%$ confidence interval $[\mathrm{CI}]: 0.52,0.97 ; 2$ or 3 vaccinations: $\mathrm{aHR}=$ $0.45,95 \%$ CI: $0.31,0.63$; and $\geq 4$ vaccinations: aHR $=$ $0.35,95 \%$ CI: $0.24,0.51)$ and in those with diabetes $(\geq 4$ vaccinations: $\mathrm{aHR}=0.37,95 \% \mathrm{CI}: 0.23,0.59), \mathrm{CCI} \geq 3$ ( $\geq 4$ vaccinations: aHR $=0.29,95 \% \mathrm{CI}: 0.18,0.46$ ), and dyslipidemia ( $\geq 4$ vaccinations: aHR $=0.30,95 \%$ CI: 0.19 , $0.48)$. The results of the sensitivity analysis of the aHRs in the noninfluenza season are listed in Table 4. A stronger protective effect against ischemic stroke was observed during the noninfluenza season. Less frequent vaccination significantly reduced the risk of ischemic stroke. Vaccination at a frequency of 2 or 3 times conferred a protective effect on the patients with AF. The protective effect was more predominant in the patients aged $\geq 75 \mathrm{y}$ (1 vaccination: $\mathrm{aHR}=0.64,95 \% \mathrm{CI}: 0.44,0.94 ; 2$ or 3 vaccinations: $\mathrm{aHR}=0.56,95 \% \mathrm{CI}: 0.39,0.81$; and $\geq 4$ vaccinations: aHR $=0.23,95 \% \mathrm{CI}: 0.14,0.39)$ and in those with diabetes ( 2 or 3 vaccinations: $\mathrm{aHR}=0.35,95 \%$ CI: $0.20,0.61 ; \geq 4$ vaccinations: $\mathrm{aHR}=0.20,95 \% \mathrm{CI}: 0.10$, 0.38 ), dyslipidemia ( 2 or 3 vaccinations: $\mathrm{aHR}=0.38,95 \%$ CI: $0.22,0.68 ; \geq 4$ vaccinations: $\mathrm{aHR}=0.19,95 \% \mathrm{CI}: 0.10$, 0.39 ), hypertension ( 2 or 3 vaccinations: $\mathrm{aHR}=0.57,95 \%$ CI: $0.41,0.78 ; \geq 4$ vaccinations: $\mathrm{aHR}=0.25,95 \% \mathrm{CI}: 0.17$, 0.38 ), and $\mathrm{CCI} \geq 3$ ( 2 or 3 vaccinations: $\mathrm{HHR}=0.40,95 \%$ CI: $0.34,0.67 ; \geq 4$ vaccinations: $\mathrm{aHR}=0.25,95 \% \mathrm{CI}: 0.14$, 0.46). During all seasons (Table 5), the trend of ischemic stroke reduction still reflected the vaccination frequency. The protective effect was more predominant in the patients aged $\geq 75$ y ( 1 vaccination: aHR $=0.68,95 \% \mathrm{CI}: 0.54$, 0.87 ; 2 or 3 vaccinations: $\mathrm{aHR}=0.49,95 \% \mathrm{CI}: 0.38,0.64$; and $\geq 4$ vaccinations: $\mathrm{aHR}=0.30,95 \% \mathrm{CI}: 0.23,0.41)$ and in those with diabetes ( 2 or 3 vaccinations: aHR $=0.52$, 95\% CI: $0.38,0.72$; $\geq 4$ vaccinations: $\mathrm{aHR}=0.29,95 \% \mathrm{CI}$ : $0.20,0.43$ ), dyslipidemia ( 2 or 3 vaccinations: $\mathrm{aHR}=0.61$, 95\% CI: $0.45,0.84 ; \geq 4$ vaccinations: $\mathrm{aHR}=0.26,95 \% \mathrm{CI}$ : $0.17,0.37$ ), hypertension ( 2 or 3 vaccinations: $\mathrm{aHR}=0.60$, 95\% CI: $0.49,0.73 ; \geq 4$ vaccinations: $\mathrm{aHR}=0.33,95 \% \mathrm{CI}$ : $0.26,0.42$ ), and $\mathrm{CCI} \geq 3$ ( 2 or 3 vaccinations: $\mathrm{aHR}=0.44$, 95\% CI: $0.32,0.60 ; \geq 4$ vaccinations: $\mathrm{aHR}=0.27,95 \%$ CI: 0.19, 0.39). Regardless of warfarin, statin, metformin, ACEI, or aspirin use, vaccination was an independent protective factor and dose-dependently reduced the risk of ischemic stroke in the patients with AF.

\section{DISCUSSION}

To date, few studies have investigated the association of the risk of ischemic stroke with influenza vaccination in patients with AF who received influenza vaccination. Hung et al. conducted a cohort study and reported that the efficacy of the dual influenza and pneumococcal vaccine is higher than that of either vaccine alone in preventing complications in elderly patients with chronic illnesses [19]. Moreover, the rate of ischemic stroke $(\mathrm{HR}=0.67$; $95 \%$ CI: $0.54,0.83$ ) was lower in elderly patients who were aged $\geq 65 \mathrm{y}$, had chronic illnesses, and received the dual influenza and pneumococcal polysaccharide vaccine than in unvaccinated patients [19]. The population and intervention used in our study differ from those used in the study of Hung et al. In our study, the intervention was influenza vaccination exhibiting a more specific efficacy than that used by Hung et al [19]. Although studies have used a similar population of elderly patients, $[13,14]$ they did not focus on patients having a high risk of ischemic stroke (i.e., patients with AF). In this study, we included a specific AF population with a risk of ischemic stroke. Our study results reveal that influenza vaccination was an independent protective factor and dose-dependently reduced the risk of ischemic stroke in the patients with $\mathrm{AF}$, irrespective of age, sex, hypertension, heart disease, or anticoagulant use. According to our review of the literature, this is the first study to provide a valuable solution for reducing the risk of ischemic stroke in patients with AF. This strategy for ischemic stroke prevention in patients with $\mathrm{AF}$ requires further investigation.

The precise mechanism through which influenza vaccination reduces the risk of ischemic stroke in patients with AF remains unknown. The protective effect of influenza vaccination is likely related to the prevention of acute infection, which can elicit both systemic and local vascular inflammatory responses [20]. Influenza increases local proinflammatory cytokine expression, platelet aggregation, and systemic inflammation marker levels and causes endothelial dysfunction and loss of the protective properties of high-density lipoproteins [2124]. All these changes can directly or indirectly stimulate thrombogenesis and exacerbate atherosclerotic plaque inflammation, which can increase the risk of stroke in combination with increased hemodynamic stress. In addition, in an experimental human influenza A study, patients treated with an oral neuraminidase inhibitor had lower levels of the proinflammatory cytokines interferon- $\gamma$, interleukin- 6 , and tumor necrosis factor- $\alpha$ in nasal washings than did those treated with a placebo. In the placebo group, the levels of these cytokines were 2- to 4-fold higher than baseline levels [25]. Considering the potential proinflammatory and prothrombotic 
Table 2: Risk of ischemic stroke in unvaccinated and vaccinated patients

\begin{tabular}{|c|c|c|c|c|c|}
\hline \multirow[b]{2}{*}{ All Group $(n=6570)$} & \multicolumn{2}{|c|}{$\begin{array}{l}\text { Unvaccinated patients (Total follow-up } \\
\text { duration: } 12291.9 \text { person-y) }\end{array}$} & \multicolumn{2}{|c|}{$\begin{array}{l}\text { Vaccinated patients (Total follow-up duration: } \\
\qquad 14810.0 \text { person-y) }\end{array}$} & \multirow[b]{2}{*}{$\operatorname{aHR}^{\dagger}(95 \% \mathrm{CI})$} \\
\hline & $\begin{array}{l}\text { No. of patients with } \\
\text { stroke }\end{array}$ & $\begin{array}{c}\text { Incidence Rate (per } \\
1000 \text { person-y) } \\
(95 \% \mathrm{CI})\end{array}$ & $\begin{array}{l}\text { No. of patients with } \\
\text { stroke }\end{array}$ & $\begin{array}{c}\text { Incidence rate (per } \\
1000 \text { person-y) } \\
(95 \% \mathrm{CI})\end{array}$ & \\
\hline \multicolumn{6}{|l|}{ Whole cohort } \\
\hline Influenza season & 286 & $2326.7(2057.1,2596.4)$ & 284 & $1917.6(1694.6,2140.7)$ & $0.59(0.50,0.71)^{* * * *}$ \\
\hline Noninfluenza season & 222 & $1806.1(1568.5,2043.6)$ & 174 & $1174.9(1000.3,1349.5)$ & $0.50(0.40,0.61)^{* * * *}$ \\
\hline All seasons & 508 & $4132.8(3773.4,4492.2)$ & 458 & $3092.5(2809.3,3375.7)$ & $0.55(0.48,0.63)^{* * * *}$ \\
\hline \multicolumn{6}{|l|}{ Age, 55-64 $y^{a}$} \\
\hline Influenza season & 60 & $1200.5(896.7,1504.3)$ & 31 & $1286.8(833.8,1739.8)$ & $0.80(0.51,1.25)$ \\
\hline Noninfluenza season & 42 & $840.4(586.2,1094.5)$ & 12 & $498.1(216.3,780.0)$ & $0.52(0.27,1.00)^{*}$ \\
\hline All seasons & 102 & $2040.9(1644.8,2436.9)$ & 43 & $1785.0(1251.4,2318.5)$ & $0.69(0.48,0.99)^{*}$ \\
\hline \multicolumn{6}{|l|}{ Age, $65-74 y^{b}$} \\
\hline Influenza season & 75 & $2217.8(1715.9,2719.8)$ & 121 & $1793.6(1474.0,2113.2)$ & $0.55(0.41,0.75)^{* * * *}$ \\
\hline Noninfluenza season & 70 & $2070.0(1585.0,2554.9)$ & 71 & $1052.5(807.6,1297.3)$ & $0.41(0.29,0.57)^{* * * *}$ \\
\hline All seasons & 145 & $4287.8(3589.9,4985.7)$ & 192 & $2846.1(2443.5,3248.7)$ & $0.48(0.39,0.61)^{* * * *}$ \\
\hline \multicolumn{6}{|l|}{ Age, $\geq 75 \mathbf{y}^{\mathrm{c}}$} \\
\hline Influenza season & 151 & $3859.6(3244.0,4475.2)$ & 132 & $2334.3(1936.0,2732.5)$ & $0.49(0.39,0.63)^{* * * *}$ \\
\hline Noninfluenza season & 110 & $2811.6(2286.2,3337.1)$ & 91 & $1609.2(1278.6,1939.9)$ & $0.47(0.35,0.62)^{* * * *}$ \\
\hline All seasons & 261 & $6671.3(5861.9,7480.6)$ & 223 & $3943.5(3425.9,4461.1)$ & $0.45(0.40,0.53)^{* * * *}$ \\
\hline \multicolumn{6}{|l|}{ Women $^{\text {d }}$} \\
\hline Influenza season & 153 & $2625.7(2209.6,3041.7)$ & 122 & $1772.1(1457.6,2086.5)$ & $0.49(0.38,0.63)^{* * * *}$ \\
\hline Noninfluenza season & 107 & $1836.2(1488.3,2184.2)$ & 85 & $1234.6(972.2,1497.1)$ & $0.53(0.39,0.72)^{* * * *}$ \\
\hline All seasons & 260 & $4461.9(3919.5,5004.3)$ & 207 & $3006.7(2597.1,3416.3)$ & $0.51(0.42,0.61)^{* * * *}$ \\
\hline \multicolumn{6}{|l|}{$\operatorname{Men}^{e}$} \\
\hline Influenza season & 133 & $2057.3(1707.7,2407.0)$ & 162 & $2044.1(1729.3,2358.8)$ & $0.74(0.58,0.95)^{*}$ \\
\hline Noninfluenza season & 115 & $1778.9(1453.8,2104.0)$ & 89 & $1123.0(889.7,1356.3)$ & $0.46(0.34,0.62)^{* * * *}$ \\
\hline All seasons & 248 & $3836.2(3358.8,4313.7)$ & 251 & $3167.0(2775.2,3558.8)$ & $0.61(0.50,0.74)^{* * * *}$ \\
\hline
\end{tabular}

${ }^{*} P<0.05{ }^{* *} P<0.01{ }^{* * *} P<0.001$

${ }^{a}$ Total follow-up durations: 4997.9 and 2409.0 person-y for unvaccinated and vaccinated patients, respectively.

${ }^{b}$ Total follow-up durations: 3381.7 and 6746.1 person-y for unvaccinated and vaccinated patients, respectively.

'Total follow-up durations: 3912.3 and 5654.9 person-y for unvaccinated and vaccinated patients, respectively.

${ }^{\mathrm{d}}$ Total follow-up durations: 5827.1 and 6884.6 person-y for unvaccinated and vaccinated patients, respectively.

${ }^{\mathrm{e}}$ Total follow-up durations: 6464.7 and 7925.4 person-y for unvaccinated and vaccinated patients, respectively.

CI: confidence interval

HR: hazard ratio

aHR: adjusted hazard ratio

†The main model was adjusted for age; sex; Charlson comorbidity index; comorbidities of diabetes, hypertension, dyslipidemia, congestive heart failure, vascular disease, pneumonia, and dialysis; urbanization level; and monthly income by using propensity scores. 
consequences of influenza, influenza vaccination might prevent the high expression of proinflammatory cytokines and reduce inflammation, viral load, and illness duration, thereby exerting a positive effect on the risk of thrombotic events such as stroke induced by influenza infection. During and after influenza epidemics, vascular death rates and hospitalizations for stroke increased [26]. Studies have reported that influenza might be the cause of this acute infection, leading to ischemic stroke,[19, 27] particularly in patients with AF who are susceptible to ischemic stroke. The Taiwan Centers for Disease Control included $>70 \%$ of circulating influenza strains in the influenza vaccine [28] and successfully reduced the rate of influenza transmission[29, 30] and risk of AF through influenza vaccination [17]. In addition, if a mismatch occurs between the circulating influenza strains and vaccine antigens, the effect of the influenza vaccine would be underestimated, thus leading to "bias toward the null hypothesis." However, the actual effect of the influenza vaccine would be high if the circulating influenza strains and vaccine antigens match. In our study, we observed that influenza vaccination independently exerted a strong dose-dependent effect on ischemic stroke prevention in the patients with AF.

The unvaccinated and vaccinated patients had different baseline characteristics (Table 1). In Taiwan, influenza vaccination has been provided free of charge and recommended for high-risk adults aged $\geq 55$ y (i.e., those with hypertension, congestive heart failure, chronic liver infection, liver cirrhosis, cardiovascular diseases, or chronic pulmonary diseases) since 1998 and for all adults aged $>65$ y since 2001 . We selected covariates on the basis of a logistic regression model. Each patient was followed to assess the risk of and protective factors for ischemic stroke. We used PSs to evaluate the following demographic characteristics: age; sex; CCI; comorbidities of diabetes, hypertension, dyslipidemia, congestive heart failure, vascular disease, pneumonia, and dialysis; urbanization level; monthly income; and warfarin, statin, metformin, aspirin, and ACEI use (Supplementary Table $1)$.

In patients with $\mathrm{AF}$, a cardiac embolus most commonly originating from the left atrium is a common cause of ischemic stroke [31]. A cardioembolic event is likely to have occurred in patients with AF who have had a stroke $[31,32]$. AF is common in elderly patients who often have a risk of other stroke types [6]. Thus, the presence of AF in a patient who had a stroke does not always imply a causal relationship [6]. Consequently, all patients with stroke, even in the presence of AF, should be investigated for other causes of stroke, particularly if such an investigation would result in different treatments. On the basis of this rationale, we investigated whether influenza vaccination reduces the risk of hemorrhagic stroke in patients with AF (data not published). The CHA2DS2-VASc score is a clinical prediction rule used to estimate the risk of stroke in patients with AF [33, 34]. Risk factors included in the CHA2DS2-VASc score are congestive heart failure, hypertension, age (65-74 or $\geq 75$ y), diabetes mellitus, prior stroke, vascular disease, or female sex [33, 34]. Hypertension is a crucial component in the management of patients with AF who have had a stroke [35]. Antihypertensive therapy, preferably including an ACEI,[36] reduces the risk of warfarinassociated intracranial hemorrhage and may reduce the rate of recurrent stroke [37]. Hence, we selected these risk factors as covariates in the main model or as an additional covariate in the sensitivity analysis (Tables 2-5).

The risk factors in the CHA2DS2-VASc score included being aged $\geq 75 \mathrm{y}$ ( 2 points) and $65-74 \mathrm{y}$ ( 1 point) $[33,34]$. Our data reveal that age is a strong risk factor for ischemic stroke in the patients with AF. The risk of ischemic stroke was higher in the elderly patients than in the young patients. Table 2 presents the risk of ischemic stroke in the unvaccinated and vaccinated patients. The stratified analysis after adjustment for PSs in the main model demonstrated that aHRs significantly decreased in the vaccinated patients, particularly in those aged 65-74 and $\geq 75 \mathrm{y}$. The aHRs of ischemic stroke were lower in the vaccinated patients than in the unvaccinated patients during all seasons. Notably, despite the small sample size of the 55-64-y-old age group, the aHRs remained significantly lower in the vaccinated patients during the noninfluenza season. A competing risk factor might be present between the influenza and noninfluenza seasons in the 55-64-y-old age group [20]. In this study, influenza vaccination exerted a stronger protective effect in more elderly patients (65-74 and $\geq 75 \mathrm{y}$ ) with AF. This finding indicates the importance of administering influenza vaccination to elderly patients and elderly patients with AF having a relatively high risk of ischemic stroke. In the 55-64-y-old age group, influenza vaccination exerted a protective effect during the noninfluenza season. This finding indicates that influenza vaccination is crucial for working-age $(<65 \mathrm{y})$ patients with $\mathrm{AF}$.

Regarding the female sex, a retrospective cohort study of approximately 100000 patients with AF conducted in 2012 reported that the risk of ischemic stroke was moderately higher in women [38]. The female sex is included as a risk factor in the CHA2DS2-VASc score $[33,34]$. Our study results reveal that the female sex was associated with a high risk of ischemic stroke in the patients with AF. The stratified analysis after adjustment for PSs in the main model revealed that the aHRs were significantly lower in the vaccinated patients, irrespective of sex, age, or season. The aHRs of ischemic stroke were lower in the vaccinated patients than in the unvaccinated patients during all seasons (women and men: aHRs = 0.51 and $0.61 ; P<0.001$ and $P<0.001$, respectively). In this study, influenza vaccination conferred a stronger protective effect on the female patients with AF. Biological and physiological characteristics defining women and 
Table 3: Sensitivity analysis of aHRs of vaccination in risk reduction of ischemic stroke in the influenza season

\begin{tabular}{|c|c|c|c|c|c|}
\hline & \multirow{3}{*}{$\begin{array}{l}\text { Unvaccinated patients } \\
\text { aHR (95\% CI) }\end{array}$} & \multicolumn{3}{|c|}{ Vaccinated patients } & \multirow{3}{*}{$P$ for trend } \\
\hline & & 1 vaccination & \multirow{2}{*}{$\frac{2 \text { or } 3 \text { vaccinations }}{\operatorname{aHR}(95 \% \mathrm{CI})}$} & \multirow{2}{*}{$\frac{\geq 4 \text { vaccinations }}{\text { aHR }(95 \% \mathrm{CI})}$} & \\
\hline & & aHR (95\% CI) & & & \\
\hline Main model ${ }^{+}$ & 1.00 & $0.91(0.72,1.15)$ & $0.62(0.49,0.79)^{*+*}$ & $0.40(0.31,0.51)^{*+*}$ & $<0.001$ \\
\hline \multicolumn{6}{|l|}{ Additional covariates ${ }^{\ddagger}$} \\
\hline Main model + warfarin & 1.00 & $0.90(0.71,1.14)$ & $0.62(0.49,0.79)^{*+*}$ & $0.39(0.30,0.50)^{* * * *}$ & $<0.001$ \\
\hline Main model + aspirin & 1.00 & $0.91(0.72,1.14)$ & $0.62(0.49,0.79)^{* * *}$ & $0.40(0.31,0.51)^{* * * *}$ & $<0.001$ \\
\hline Main model + statin & 1.00 & $0.91(0.72,1.15)$ & $0.62(0.49,0.79)^{* * *}$ & $0.40(0.31,0.51)^{* * * *}$ & $<0.001$ \\
\hline Main model + ACEI & 1.00 & $0.91(0.72,1.15)$ & $0.62(0.49,0.79)^{*+*}$ & $0.40(0.31,0.51)^{* * * *}$ & $<0.001$ \\
\hline Main model + metformin & 1.00 & $0.91(0.72,1.14)$ & $0.62(0.49,0.78)^{*+*}$ & $0.39(0.31,0.51)^{* * *}$ & $<0.001$ \\
\hline \multicolumn{6}{|l|}{ Subgroup effects } \\
\hline \multicolumn{6}{|l|}{ Age, y } \\
\hline $55-74$ & 1.00 & $1.09(0.77,1.53)$ & $0.87(0.63,1.21)$ & $0.50(0.36,0.70)^{* * * *}$ & $<0.001$ \\
\hline$\geq 75$ & 1.00 & $0.71(0.52,0.97)^{*}$ & $0.45(0.31,0.63)^{*+*}$ & $0.35(0.24,0.51)^{*+* *}$ & $<0.001$ \\
\hline \multicolumn{6}{|l|}{ Sex } \\
\hline Women & 1.00 & $0.65(0.45,0.94)^{*}$ & $0.47(0.33,0.68)^{*+*}$ & $0.41(0.29,0.58)^{* * * *}$ & $<0.001$ \\
\hline Men & 1.00 & $1.22(0.90,1.67)$ & $0.81(0.59,1.13)$ & $0.40(0.28,0.57)^{* * *}$ & $<0.001$ \\
\hline \multicolumn{6}{|l|}{$\mathrm{CCI}^{+}$} \\
\hline 0 & 1.00 & $0.62(0.34,1.13)$ & $0.57(0.32,1.00)$ & $0.39(0.22,0.68)^{* * * *}$ & 0.001 \\
\hline 1 & 1.00 & $0.81(0.47,1.37)$ & $0.74(0.46,1.18)$ & $0.46(0.28,0.74)^{* * *}$ & 0.002 \\
\hline 2 & 1.00 & $1.21(0.76,1.91)$ & $0.64(0.38,1.07)$ & $0.40(0.24,0.66)^{* * * *}$ & $<0.001$ \\
\hline$\geq 3$ & 1.00 & $0.87(0.60,1.26)$ & $0.46(0.31,0.70)^{*+*}$ & $0.29(0.18,0.46)^{* * * *}$ & $<.001$ \\
\hline \multicolumn{6}{|l|}{ Diabetes } \\
\hline No & 1.00 & $0.86(0.64,1.15)$ & $0.57(0.43,0.78)^{*+*}$ & $0.39(0.29,0.53)^{* * *+}$ & $<0.001$ \\
\hline Yes & 1.00 & $0.97(0.66,1.42)$ & $0.66(0.45,0.99)^{* * *}$ & $0.37(0.23,0.59)^{* * * *}$ & $<0.001$ \\
\hline \multicolumn{6}{|l|}{ Dyslipidemia } \\
\hline No & 1.00 & $1.00(0.76,1.32)$ & $0.52(0.38,0.72)^{*+*}$ & $0.42(0.31,0.57)^{* * *}$ & $<0.001$ \\
\hline Yes & 1.00 & $0.71(0.46,1.08)$ & $0.78(0.54,1.13)$ & $0.30(0.19,0.48)^{* * * *}$ & $<0.001$ \\
\hline \multicolumn{6}{|l|}{ Hypertension } \\
\hline No & 1.00 & $0.53(0.31,0.92)^{*}$ & $0.57(0.34,0.94)^{*}$ & $0.36(0.22,0.60)^{m+* *}$ & $<0.001$ \\
\hline Yes & 1.00 & $1.04(0.80,1.35)$ & $0.62(0.47,0.81)^{*+*}$ & $0.39(0.29,0.53)^{* * * *}$ & $<0.001$ \\
\hline \multicolumn{6}{|l|}{ Warfarin } \\
\hline$<28 \mathrm{cDDD}$ & 1.00 & $0.93(0.69,1.24)$ & $0.56(0.41,0.76)^{* * *}$ & $0.39(0.28,0.54)^{*+*}$ & $<0.001$ \\
\hline$\geq 28 \mathrm{cDDD}$ & 1.00 & $0.85(0.58,1.26)$ & $0.71(0.49,1.03)$ & $0.39(0.26,0.56)^{* * * *}$ & $<0.001$ \\
\hline \multicolumn{6}{|l|}{ Aspirin } \\
\hline$<28 \mathrm{cDDD}$ & 1.00 & $0.90(0.55,1.47)$ & $0.49(0.28,0.85)^{* *}$ & $0.42(0.22,0.80)^{* * *}$ & $<0.001$ \\
\hline$\geq 28 \mathrm{cDDD}$ & 1.00 & $0.87(0.67,1.14)$ & $0.64(0.49,0.84)^{* *}$ & $0.37(0.28,0.49)^{* * * *}$ & $<0.001$ \\
\hline \multicolumn{6}{|l|}{ Statin } \\
\hline$<28 \mathrm{cDDD}$ & 1.00 & $0.89(0.67,1.18)$ & $0.53(0.39,0.72)^{*+*}$ & $0.43(0.32,0.59)^{* * * *}$ & $<0.001$ \\
\hline$\geq 28 \mathrm{cDDD}$ & 1.00 & $0.93(0.62,1.41)$ & $0.76(0.52,1.11)$ & $0.34(0.22,0.51)^{* * *}$ & $<0.001$ \\
\hline \multicolumn{6}{|l|}{ ACEI } \\
\hline$<28 \mathrm{cDDD}$ & 1.00 & $0.58(0.34,1.02)$ & $0.49(0.28,0.85)^{*}$ & $0.33(0.17,0.62)^{* * *}$ & $<0.001$ \\
\hline$\geq 28 \mathrm{cDDD}$ & 1.00 & $1.01(0.78,1.32)$ & $0.67(0.51,0.87)^{* *}$ & $0.42(0.32,0.55)^{m * *}$ & $<0.001$ \\
\hline \multicolumn{6}{|l|}{ Metformin } \\
\hline$<28 \mathrm{cDDD}$ & 1.00 & $0.83(0.63,1.10)$ & $0.59(0.44,0.78)^{*+*}$ & $0.41(0.31,0.54)^{*+* *}$ & $<0.001$ \\
\hline$\geq 28 \mathrm{cDDD}$ & 1.00 & $1.09(0.70,1.70)$ & $0.68(0.43,1.08)$ & $0.35(0.21,0.58)^{* * *}$ & $<0.001$ \\
\hline
\end{tabular}

"P<0.05" $P<0.01{ }^{* * * *} P<0.001$

HR: hazard ratio

aHR: adjusted hazard ratio

${ }^{+}$CCI: Charlson comorbidity index

†The main model was adjusted for age; sex; Charlson comorbidity index; comorbidities of diabetes, hypertension, dyslipidemia, congestive heart failure, vascular disease, pneumonia, and dialysis; urbanization level; and monthly income by using propensity scores.

${ }^{*}$ The models were adjusted for covariates in the main model and each additional listed covariate. 
men may exert differential effects on disease outcomes after pathogen exposure. In addition, women and men differ in their reproductive organs and thus sex hormone concentrations. Studies conducted in Denmark and Canada using hospitalization rates as an indicator of influenza severity have reported that the risk of influenza was higher in men than in women across all age groups during influenza virus outbreaks [39, 40]. A study conducted in Switzerland demonstrated an increased influenza-related death rate in men (aged >60 y) during the 1969-1999 season,[41] partly supporting the findings from Denmark and Canada. Overall, men had a higher risk of influenzarelated mortality, with a male-to-female ratio of 1:3 [42]. A competing risk factor may be present between men and women during influenza and noninfluenza seasons, which may be the reason for our observation of significantly lower aHRs in the vaccinated patients during the influenza season, particularly in the female patients. By contrast, the aHRs were significantly lower in the vaccinated male patients during the noninfluenza season (Table 2).

As presented in Tables 3 and 4, influenza vaccination dose-dependently reduced the risk of ischemic stroke in all the subgroups and the main model with additional covariates (warfarin, statin, metformin, ACEI, or aspirin use) during different seasons. According to all the aHRs, vaccination significantly reduced the risk of ischemic stroke in all the subgroups, regardless of comorbidities or drug use $(P<0.001)$. The outcomes for vaccination imply that this intervention may exert an independent protective effect against the risk of ischemic stroke in patients with AF. No study has evaluated the protective effect of influenza vaccination in patients with drug use, which might reduce the risk of stroke in patients with AF. This is the first study to investigate the effect of influenza vaccination on the risk of ischemic stroke in patients with AF with or without drug use. Our study results reveal that influenza vaccination independently exerted a doseresponse effect against ischemic stroke in the patients with $\mathrm{AF}$, regardless of the presence of diabetes, hypertension, dyslipidemia, congestive heart failure, or vascular disease or statin, metformin, warfarin, or ACEI use.

We obtained several major novel findings. Few studies have investigated the association of influenza vaccination with the risk of ischemic stroke in patients with AF. Although studies have reported that the risk of influenza-related mortality and ischemic stroke is high in patients with $\mathrm{AF}$, adequate evidence on solutions to reduce the mortality and risk of ischemic stroke in patients with AF is not available. Our findings indicate that influenza vaccination exerted a dose-dependent protective effect against the risk of ischemic stroke in the patients with AF. The major solution might be the regular administration of influenza vaccine to patients with AF, particularly to those having risk factors for ischemic stroke, such as hypertension, dyslipidemia, diabetes, cerebrovascular disease, and a high CHADS2 score. Tables 3-5 list the results of the sensitivity analysis of the aHRs of age, sex, CCI, comorbidities, urbanization level, and monthly income in the PS analysis. The models were adjusted for covariates in the main model and each additional covariate to estimate the reduction in the risk of ischemic stroke during the follow-up period. The dose-dependent protective effect of influenza vaccination was observed regardless of age, sex, CCI, comorbidities, urbanization level, monthly income, or drug use in the analysis stratified by different frequencies of influenza vaccination. The dose-dependent protective effect of influenza vaccination was observed for different conditional states. In addition, this study is the first to evaluate the dose-response effect of influenza vaccination on the risk of ischemic stroke in patients with AF. Our results reveal that only one influenza vaccination was less effective in reducing the risk of ischemic stroke. A high frequency of influenza vaccination exerted a more significant protective effect against ischemic stroke in the patients with AF. The strength of the present study is its large sample size. The results suggest that the incidence of ischemic stroke decreased in the patients with AF through the implementation of preventive strategies such as influenza vaccination. This is the first study to demonstrate that influenza vaccination exerts a dose-response effect against ischemic stroke in patients with AF who have risk factors for ischemic stroke by reducing the incidence of ischemic stroke, particularly in patients aged $65-74$ and $\geq 75 \mathrm{y}$.

In this study, the magnitude of the bias demonstrated by the associations observed during the noninfluenza season was sufficient to entirely account for the associations observed during the influenza season. A competing risk factor is present between the influenza and noninfluenza seasons. Studies have reported an increased risk of hospital admission and a high mortality rate among elderly men during the influenza season [43-45]. High mortality during the influenza season might mask the incidence of ischemic stroke episodes, and patients with AF might die before developing ischemic stroke. This observation is attributable to influenza vaccination exerting a stronger protective effect against ischemic stroke during the noninfluenza season (Tables 3 and 4). We noted a similar phenomenon in our previous study [20].

In Taiwan, the most frequently used vaccines are influenza and pneumococcal vaccines. However, introduction of the pneumococcal vaccine into the national immunization program is complex and costly. With financial support from a nongovernmental organization, the pneumococcal vaccine has been provided to elderly people aged $\geq 75$ y since 2007 [46]. The overall vaccination rate was $<1 \%$ in Taiwan before 2007 [47]. Compared with the influenza vaccine, the administration of other vaccines was relatively rare. These rare cases might not influence our results. Moreover, considering the magnitude and significance of the observed effects, it is unlikely that these limitations compromised the results. 
Table 4: Sensitivity analysis of aHRs of vaccination in risk reduction of ischemic stroke in the noninfluenza season

\begin{tabular}{|c|c|c|c|c|c|}
\hline & \multirow{3}{*}{$\begin{array}{c}\text { Unvaccinated patients } \\
\text { aHR }(95 \% \mathrm{CI})\end{array}$} & \multicolumn{3}{|c|}{ Vaccinated patients } & \multirow{3}{*}{$P$ for trend } \\
\hline & & \multirow{2}{*}{$\frac{1}{\mathrm{aHR}(95 \% \mathrm{CI})}$} & \multirow{2}{*}{$\frac{2 \text { or } 3}{\operatorname{aHR}(95 \% \mathrm{CI})}$} & \multirow{2}{*}{$\begin{array}{c}\geq 4 \\
\text { aHR }(95 \% \mathrm{CI})\end{array}$} & \\
\hline & & & & & \\
\hline Main model ${ }^{+}$ & 1.00 & $0.73(0.55,0.97)^{*}$ & $0.58(0.44,0.77)^{*+*}$ & $0.28(0.20,0.40)^{*+*}$ & $<0.001$ \\
\hline \multicolumn{6}{|l|}{ Additional covariates ${ }^{\ddagger}$} \\
\hline Main model + warfarin & 1.00 & $0.73(0.55,0.98)^{*}$ & $0.58(0.44,0.77)^{*+*}$ & $0.29(0.21,0.40)^{* * * *}$ & $<0.001$ \\
\hline Main model + aspirin & 1.00 & $0.74(0.55,0.98)^{*}$ & $0.60(0.45,0.79)^{*+*}$ & $0.29(0.21,0.41)^{* * * *}$ & $<0.001$ \\
\hline Main model + statin & 1.00 & $0.73(0.55,0.97)^{*}$ & $0.59(0.44,0.78)^{* * *}$ & $0.28(0.20,0.40)^{* * * *}$ & $<0.001$ \\
\hline Main model + ACEI & 1.00 & $0.73(0.55,0.98)^{*}$ & $0.59(0.44,0.78)^{*+*}$ & $0.28(0.20,0.40)^{* * * *}$ & $<0.001$ \\
\hline Main model + metformin & 1.00 & $0.73(0.55,0.97)^{*}$ & $0.58(0.44,0.77)^{*+*}$ & $0.28(0.20,0.39)^{* * * *}$ & $<0.001$ \\
\hline \multicolumn{6}{|l|}{ Subgroup effects } \\
\hline \multicolumn{6}{|l|}{ Age, y } \\
\hline $55-74$ & 1.00 & $0.78(0.51,1.19)$ & $0.62(0.41,0.94)^{*}$ & $0.38(0.25,0.59)^{* * * *}$ & $<0.001$ \\
\hline$\geq 75$ & 1.00 & $0.64(0.44,0.94)^{*}$ & $0.56(0.39,0.81)^{* *}$ & $0.23(0.14,0.39)^{* * * *}$ & $<0.001$ \\
\hline \multicolumn{6}{|l|}{ Sex } \\
\hline Women & 1.00 & $0.83(0.56,1.23)$ & $0.62(0.42,0.92)^{*}$ & $0.27(0.16,0.44)^{* * * *}$ & $<0.001$ \\
\hline Men & 1.00 & $0.64(0.43,0.97)^{*}$ & $0.55(0.37,0.81)^{* *}$ & $0.29(0.18,0.45)^{* * *}$ & $<0.001$ \\
\hline \multicolumn{6}{|l|}{$\mathrm{CCI}^{+}$} \\
\hline 0 & 1.00 & $0.91(0.47,1.74)$ & $0.76(0.39,1.48)$ & $0.49(0.25,0.96)^{*}$ & 0.037 \\
\hline 1 & 1.00 & $0.51(0.25,1.04)$ & $0.74(0.43,1.26)$ & $0.33(0.18,0.62)^{* * *}$ & 0.001 \\
\hline 2 & 1.00 & $0.67(0.37,1.23)$ & $0.55(0.30,0.99)^{*}$ & $0.29(0.19,0.48)^{* * * *}$ & $<0.001$ \\
\hline$\geq 3$ & 1.00 & $0.76(0.49,1.20)$ & $0.40(0.24,0.67)^{*+*}$ & $0.25(0.14,0.46)^{* * * *}$ & $<0.001$ \\
\hline \multicolumn{6}{|l|}{ Diabetes } \\
\hline No & 1.00 & $0.64(0.44,0.94)^{*}$ & $0.72(0.52,1.00)$ & $0.33(0.22,0.49)^{* * * *}$ & $<0.001$ \\
\hline Yes & 1.00 & $0.86(0.56,1.33)$ & $0.35(0.20,0.61)^{* * *}$ & $0.20(0.10,0.38)^{* * * *}$ & $<0.001$ \\
\hline \multicolumn{6}{|l|}{ Dyslipidemia } \\
\hline No & 1.00 & $0.56(0.38,0.83)^{* * *}$ & $0.68(0.49,0.94)^{*}$ & $0.33(0.23,0.49)^{* * * *}$ & $<0.001$ \\
\hline Yes & 1.00 & $1.05(0.68,1.61)$ & $0.38(0.22,0.68)^{*+*}$ & $0.19(0.10,0.36)^{* * * *}$ & $<0.001$ \\
\hline \multicolumn{6}{|l|}{ Hypertension } \\
\hline No & 1.00 & $0.69(0.38,1.25)$ & $0.56(0.30,1.04)$ & $0.36(0.19,0.68)^{* * *}$ & $<0.001$ \\
\hline Yes & 1.00 & $0.74(0.54,1.03)$ & $0.57(0.41,0.78)^{*+*}$ & $0.25(0.17,0.38)^{* * * *}$ & $<0.001$ \\
\hline \multicolumn{6}{|l|}{ Warfarin } \\
\hline$<28 \mathrm{cDDD}$ & 1.00 & $0.82(0.59,1.12)$ & $0.56(0.40,0.78)^{*+*}$ & $0.26(0.17,0.40)^{*+*}$ & $<0.001$ \\
\hline$\geq 28 \mathrm{cDDD}$ & 1.00 & $0.51(0.27,0.96)^{*}$ & $0.65(0.38,1.11)$ & $0.32(0.18,0.57)^{* * * *}$ & $<0.001$ \\
\hline \multicolumn{6}{|l|}{ Aspirin } \\
\hline$<28 \mathrm{cDDD}$ & 1.00 & $0.69(0.35,1.37)$ & $0.58(0.31,1.10)$ & $0.44(0.21,0.92)^{*}$ & 0.011 \\
\hline$\geq 28 \mathrm{cDDD}$ & 1.00 & $0.71(0.51,0.97)^{*}$ & $0.57(0.42,0.78)^{*+*}$ & $0.25(0.17,0.36)^{* * * *}$ & $<0.001$ \\
\hline \multicolumn{6}{|l|}{ Statin } \\
\hline$<28 \mathrm{cDDD}$ & 1.00 & $0.64(0.45,0.92)^{*}$ & $0.50(0.35,0.71)^{*+*}$ & $0.29(0.19,0.44)^{* * *+}$ & $<0.001$ \\
\hline$\geq 28 \mathrm{cDDD}$ & 1.00 & $0.93(0.57,1.53)$ & $0.75(0.47,1.19)$ & $0.27(0.15,0.48)^{* * *}$ & $<0.001$ \\
\hline \multicolumn{6}{|l|}{ ACEI } \\
\hline$<28 \mathrm{cDDD}$ & 1.00 & $0.37(0.17,0.80)^{*}$ & $0.35(0.17,0.73)^{* *}$ & $0.47(0.24,0.91)^{*}$ & $<0.001$ \\
\hline$\geq 28 \mathrm{cDDD}$ & 1.00 & $0.86(0.63,1.17)$ & $0.66(0.48,0.90)^{* *}$ & $0.26(0.18,0.38)^{m * *}$ & $<0.001$ \\
\hline \multicolumn{6}{|l|}{ Metformin } \\
\hline$<28 \mathrm{cDDD}$ & 1.00 & $0.66(0.46,0.93)^{*}$ & $0.64(0.46,0.88)^{* *}$ & $0.30(0.20,0.44)^{* * * *}$ & $<0.001$ \\
\hline$\geq 28 \mathrm{cDDD}$ & 1.00 & $0.93(0.56,1.55)$ & $0.45(0.25,0.82)^{* *}$ & $0.25(0.13,0.49)^{* * * *}$ & $<0.001$ \\
\hline
\end{tabular}

"P $<0.05{ }^{* *} P<0.01{ }^{* * *} P<0.001$

HR: hazard ratio

aHR: adjusted hazard ratio

${ }^{+}$CCI: Charlson comorbidity index

†The main model was adjusted for age; sex; Charlson comorbidity index; comorbidities of diabetes, hypertension, dyslipidemia, congestive heart failure, vascular disease, pneumonia, and dialysis; urbanization level; and monthly income by using propensity scores.

${ }^{*}$ The models were adjusted for covariates in the main model and each additional listed covariate. 
Table 5: Sensitivity analysis of aHRs of vaccination in risk reduction of ischemic stroke in all seasons

\begin{tabular}{|c|c|c|c|c|c|}
\hline & \multirow{3}{*}{$\begin{array}{c}\text { Unvaccinated patients } \\
\text { aHR }(95 \% \mathrm{CI})\end{array}$} & \multicolumn{3}{|c|}{ Vaccinated patients } & \multirow{3}{*}{$P$ for trenc } \\
\hline & & \multirow{2}{*}{$\frac{1}{\operatorname{aHR}(95 \% \mathrm{CI})}$} & \multirow{2}{*}{$\frac{2 \text { or } 3}{\operatorname{aHR}(95 \% \mathrm{CI})}$} & \multirow{2}{*}{$\begin{array}{c}\geq 4 \\
\text { aHR }(95 \% \mathrm{CI})\end{array}$} & \\
\hline & & & & & \\
\hline Main model ${ }^{+}$ & 1.00 & $0.83(0.69,1.00)^{*}$ & $0.60(0.50,0.72)^{*+*}$ & $0.35(0.29,0.43)^{* * * *}$ & $<0.001$ \\
\hline \multicolumn{6}{|l|}{ Additional covariates ${ }^{\ddagger}$} \\
\hline Main model + warfarin & 1.00 & $0.83(0.69,0.99)^{*}$ & $0.60(0.50,0.73)^{*+*}$ & $0.34(0.28,0.42)^{* * * *}$ & $<0.001$ \\
\hline Main model + aspirin & 1.00 & $0.83(0.69,1.00)^{*}$ & $0.61(0.51,0.73)^{* * *+}$ & $0.35(0.29,0.43)^{* * * *}$ & $<0.001$ \\
\hline Main model + statin & 1.00 & $0.83(0.69,1.00)^{*}$ & $0.60(0.50,0.73)^{* * *}$ & $0.35(0.29,0.43)^{* * * *}$ & $<0.001$ \\
\hline Main model + ACEI & 1.00 & $0.83(0.69,1.00)^{*}$ & $0.60(0.50,0.73)^{*+*}$ & $0.35(0.29,0.43)^{* * * *}$ & $<0.001$ \\
\hline Main model + metformin & 1.00 & $0.83(0.69,0.99)^{*}$ & $0.60(0.50,0.72)^{*+*}$ & $0.35(0.28,0.42)^{n+*}$ & $<0.001$ \\
\hline \multicolumn{6}{|l|}{ Subgroup effects } \\
\hline \multicolumn{6}{|l|}{ Age, y } \\
\hline $55-74$ & 1.00 & $0.95(0.73,1.24)$ & $0.76(0.59,0.98)^{*}$ & $0.45(0.35,0.59)^{* * * *}$ & $<0.001$ \\
\hline$\geq 75$ & 1.00 & $0.68(0.54,0.87)^{* *}$ & $0.49(0.38,0.64)^{*+*+}$ & $0.30(0.23,0.41)^{* * * *}$ & $<0.001$ \\
\hline \multicolumn{6}{|l|}{ Sex } \\
\hline Women & 1.00 & $0.72(0.55,0.94)^{*}$ & $0.53(0.41,0.69)^{*+*}$ & $0.35(0.27,0.47)^{* * *}$ & $<0.001$ \\
\hline Men & 1.00 & $0.95(0.74,1.21)$ & $0.69(0.53,0.88)^{* *}$ & $0.35(0.26,0.46)^{* * * *}$ & $<0.001$ \\
\hline \multicolumn{6}{|l|}{$\mathrm{CCI}^{+}$} \\
\hline 0 & 1.00 & $0.73(0.47,1.14)$ & $0.64(0.42,0.99)^{*}$ & $0.43(0.28,0.66)^{* * * *}$ & $<0.001$ \\
\hline 1 & 1.00 & $0.67(0.44,1.03)$ & $0.74(0.52,1.05)$ & $0.40(0.28,0.59)^{* * * *}$ & $<0.001$ \\
\hline 2 & 1.00 & $0.95(0.66,1.37)$ & $0.59(0.40,0.88)^{* *}$ & $0.27(0.18,0.42)^{* * * *}$ & $<0.001$ \\
\hline$\geq 3$ & 1.00 & $0.83(0.62,1.10)$ & $0.44(0.32,0.60)^{*+* *}$ & $0.27(0.19,0.39)^{* * * *}$ & $<0.001$ \\
\hline \multicolumn{6}{|l|}{ Diabetes } \\
\hline No & 1.00 & $0.77(0.61,0.97)^{*}$ & $0.63(0.51,0.79)^{*+* *}$ & $0.37(0.29,0.47)^{* * * *}$ & $<0.001$ \\
\hline Yes & 1.00 & $0.92(0.69,1.23)$ & $0.52(0.38,0.72)^{* * * *}$ & $0.29(0.20,0.43)^{\ldots+* *}$ & $<0.001$ \\
\hline \multicolumn{6}{|l|}{ Dyslipidemia } \\
\hline No & 1.00 & $0.81(0.64,1.01)$ & $0.59(0.47,0.74)^{*+*}$ & $0.38(0.30,0.49)^{* * * *}$ & $<0.001$ \\
\hline Yes & 1.00 & $0.85(0.63,1.15)$ & $0.61(0.45,0.84)^{* *}$ & $0.26(0.17,0.37)^{* * *}$ & $<0.001$ \\
\hline \multicolumn{6}{|l|}{ Hypertension } \\
\hline No & 1.00 & $0.59(0.40,0.89)^{*}$ & $0.56(0.38,0.83)^{*+* *}$ & $0.36(0.24,0.54)^{* * * *}$ & $<0.001$ \\
\hline Yes & 1.00 & $0.91(0.74,1.11)$ & $0.60(0.49,0.73)^{*+* *}$ & $0.33(0.26,0.42)^{n+*}$ & $<0.001$ \\
\hline \multicolumn{6}{|l|}{ Warfarin } \\
\hline$<28 \mathrm{cDDD}$ & 1.00 & $0.87(0.70,1.08)$ & $0.56(0.44,0.70)^{* * * *}$ & $0.33(0.25,0.43)^{* * * *}$ & $<0.001$ \\
\hline$\geq 28 \mathrm{cDDD}$ & 1.00 & $0.73(0.52,1.01)$ & $0.69(0.51,0.93)^{*}$ & $0.36(0.27,0.50)^{* * * *}$ & $<0.001$ \\
\hline \multicolumn{6}{|l|}{ Aspirin } \\
\hline$<28 \mathrm{cDDD}$ & 1.00 & $0.82(0.55,1.22)$ & $0.52(0.34,0.80)^{* *}$ & $0.43(0.26,0.70)^{* * * *}$ & $<0.001$ \\
\hline$\geq 28 \mathrm{cDDD}$ & 1.00 & $0.80(0.65,0.98)^{*}$ & $0.61(0.50,0.74)^{*+* *}$ & $0.32(0.26,0.40)^{* * * *}$ & $<0.001$ \\
\hline \multicolumn{6}{|l|}{ Statin } \\
\hline$<28 \mathrm{cDDD}$ & 1.00 & $0.78(0.63,0.97)^{*}$ & $0.51(0.41,0.65)^{* * *}$ & $0.37(0.29,0.47)^{\ldots+*}$ & $<0.001$ \\
\hline$\geq 28 \mathrm{cDDD}$ & 1.00 & $0.93(0.68,1.28)$ & $0.76(0.56,1.01)$ & $0.31(0.22,0.44)^{* * * *}$ & $<0.001$ \\
\hline \multicolumn{6}{|l|}{ ACEI } \\
\hline$<28 \mathrm{cDDD}$ & 1.00 & $0.49(0.31,0.77)^{* *}$ & $0.43(0.28,0.67)^{*+*}$ & $0.38(0.24,0.61)^{* * * *}$ & $<0.001$ \\
\hline$\geq 28 \mathrm{cDDD}$ & 1.00 & $0.95(0.77,1.16)$ & $0.66(0.54,0.81)^{*+* *}$ & $0.35(0.28,0.44)^{m * *}$ & $<0.001$ \\
\hline \multicolumn{6}{|l|}{ Metformin } \\
\hline$<28 \mathrm{cDDD}$ & 1.00 & $0.76(0.61,0.94)^{*}$ & $0.61(0.49,0.75)^{*+*}$ & $0.36(0.29,0.46)^{\ldots * *}$ & $<0.001$ \\
\hline$\geq 28 \mathrm{cDDD}$ & 1.00 & $1.02(0.73,1.42)$ & $0.58(0.40,0.83)^{* * *}$ & $0.31(0.21,0.46)^{* * * *}$ & $<0.001$ \\
\hline
\end{tabular}

"P<0.05" $P<0.01{ }^{* * * *} P<0.001$

HR: hazard ratio

aHR: adjusted hazard ratio

${ }^{+}$CCI: Charlson comorbidity index

†The main model was adjusted for age; sex; Charlson comorbidity index; comorbidities of diabetes, hypertension, dyslipidemia, congestive heart failure, vascular disease, pneumonia, and dialysis; urbanization level; and monthly income by using propensity scores.

${ }^{*}$ The models were adjusted for covariates in the main model and each additional listed covariate. 
This study has some potential limitations. Observational studies have suggested that lifestyle factors, particularly ethnicity, family history, genetic disorders, physical activity, and other potential confounding factors, are associated with the risk of ischemic stroke. However, methodological concerns may obscure the precise relationship between these factors and the risk of ischemic stroke. In this study, we used PSs to adjust age, sex, CCI, comorbidities, urbanization level, and monthly income. The urbanization level and monthly income are invalidated alternatives for lifestyle factors. To obtain such information, a large randomized trial applying a suitable regimen to well-selected patients to compare standard approaches is necessary. Moreover, the diagnoses of ischemic stroke and all other comorbidities were completely dependent on ICD-9-CM codes. However, the National Health Insurance Administration randomly reviews charts and interviews patients to validate diagnoses. A study conducted in Taiwan reported a positive predictive value (PPV) of $88.4 \%$ (95\% CI: $86.8 \%, 89.8 \%)$ and sensitivity of $97.3 \%(95 \% \mathrm{CI}$, $96.4 \%, 98.1 \%$ ) for diagnoses. The PPV of the diagnosis of ischemic stroke, AF, or a disease included in the NHI claims data was high [48, 49]. Hospitals with outlier diagnoses and practices may be audited and subsequently heavily penalized if malpractices or discrepancies are discovered. In the absence of actual patient exposure to influenza disease (as evidenced by antibody titers), deriving a mechanism for administration of the vaccine to reduce the risk of ischemic stroke will be challenging. A randomized controlled trial should be designed to test the viral serotype frequency in a cohort to verify actual patient exposure to influenza disease. However, our study results indicate a possibility that a high frequency of influenza vaccination exerted a significant protective effect against ischemic stroke in the patients with AF. Another limitation is that several unmeasured confounders, including body mass index, smoking, alcohol intake, and over-the-counter drug use, associated with ischemic stroke are not available in the NHIRD. However, considering the magnitude and significance of the observed effects, it is unlikely that these limitations compromised the results. Finally, our study was not a prospective randomized blinded study; thus, a causeeffect relationship could not be established. The findings of the present study suggest that influenza vaccination exerts a significant protective effect. Randomized studies are required to verify these findings.

\section{MATERIALS AND METHODS}

The National Health Insurance (NHI) program, established in 1995, currently provides comprehensive health insurance coverage to $98 \%$ of more than 23 million people in Taiwan. In this study, we used data from the National Health Insurance Research Database (NHIRD). No significant differences have been observed in age, sex, or health care costs between people sampled in the NHIRD and all NHI enrollees. According to the Taiwan Centers for Disease Control, the influenza season extends from October to March. Data in the NHIRD that can be used to identify patients or care providers, including medical institutions and physicians, are encrypted before being sent to the National Health Research Institutes for database construction and are further scrambled before being released to researchers. Theoretically, querying the data alone to identify people at any level is impractical. All researchers using the NHIRD and its data subsets must sign a written agreement declaring that they have no intention of attempting to obtain information that could potentially violate the privacy of patients or care providers $[18,19]$.

The study cohort comprised all patients diagnosed as having AF (according to International Classification of Diseases, Ninth Revision, Clinical Modification [ICD9-CM] codes) at health care facilities in Taiwan $(n=14$ 454) before January 1, 2005. The last follow-up date was December 31, 2013. We excluded all patients without a subsequent outpatient visit, emergency department visit, or inpatient hospitalization for AF within $12 \mathrm{mo}$ of the first presentation $(n=1825)$ because they were considered to not have AF. In addition, we excluded 6059 patients who were younger than 55 y $(n=1699)$, had any inpatient or outpatient diagnosis related to stroke before the enrollment date, did not die of ischemic stroke before December 31, $2013(\mathrm{n}=2236)$, or had received an influenza or pneumococcal polysaccharide vaccine before the enrollment date $(n=2124)$.

In Taiwan, influenza vaccination has been provided free of charge and recommended for high-risk adults aged $\geq 55$ y (i.e., those with type 2 diabetes, chronic liver infection, liver cirrhosis, cardiovascular diseases, or chronic pulmonary diseases) since 1998 and for all adults aged $>65$ y since 2001. In this study, the vaccination status was identified using the ICD-9-CM code V048 and/or identified on the basis of vaccine use (confirmed using drug codes) $[19,20]$. Our final study cohort comprised 6570 patients diagnosed as having AF in Taiwan before January 1, 2005. Of these patients, 2547 and 4023 received and did not receive influenza vaccination, respectively. We selected covariates on the basis of a logistic regression model. Each patient was followed to assess the risk of and protective factors for ischemic stroke. We used propensity scores (PSs) to evaluate the following demographic characteristics: age; sex; Charlson comorbidity index (CCI); comorbidities of diabetes, hypertension, dyslipidemia, congestive heart failure, vascular disease, pneumonia, and dialysis; urbanization level; monthly income; and warfarin, statin, metformin, aspirin, and angiotensin-converting enzyme inhibitor (ACEI) use (Supplementary Table 1). All potential confounders (Supplementary Table 1) were included in the list of regressors (C statistic: 0.68 ). Moreover, all potential confounders observed within 6 mo before and after the index 
date until the endpoint (ischemic stroke) were identified according to the main diagnosis code for the first admission or according to more than 2 repeated main diagnosis codes for visits to an outpatient department. The patients who received the prescribed drugs for $<28$ cumulative defined daily doses (cDDDs) were defined as nonusers. We derived PSs by using a logistic regression model to estimate the effect of vaccination by accounting for covariates that predicted receiving the intervention (vaccine). This method was used in an observational study to reduce selection bias [21]. The covariates in the main model were adjusted for the PSs of age, sex, CCI, comorbidities, urbanization level (urban, suburban, and rural), and monthly income (none; NT\$1-NT\$21,000; NT\$21,000-NT\$33,300; and $\geq N T \$ 33,301$; NT\$ represents New Taiwan dollars; Table 2 ). The endpoint was the incidence of ischemic stroke (ICD9-CM codes 433-437) in the vaccinated or unvaccinated patients with a subsequent outpatient visit, emergency department visit, or inpatient hospitalization for ischemic stroke within $12 \mathrm{mo}$; moreover, the unvaccinated patients served as the reference arm. Because the protective effect of each vaccination is specific to that influenza season, evaluating the noninfluenza season can indicate the possible contribution of bias to estimates obtained during the influenza season. In addition, the relationship between the seasonal effect of vaccination and the risk of ischemic stroke was analyzed. The cumulative incidence of ischemic stroke in the vaccinated and unvaccinated patients with AF was estimated using the Kaplan-Meier method. To examine the effect of the total number of vaccinations on the cumulative incidence of ischemic stroke, we categorized the patients into 4 groups according to the vaccination status: unvaccinated and 1,2 to 3 , and $\geq 4$ total vaccinations.

We used a Cox proportional hazard model with time-dependent covariates to prevent immortal time bias. A Cox proportional hazard model was used to calculate the hazard ratios (HRs) of ischemic stroke in the vaccinated and unvaccinated patients with AF [22]. The index date was January 1, 2005. All covariates observed 6 mo before and after the index date were included. In a multivariate analysis, the HRs were adjusted for age; sex; CCI; comorbidities of diabetes, hypertension, dyslipidemia, congestive heart failure, vascular disease, pneumonia, and dialysis; urbanization level; monthly income; and drug use. A stratified analysis was conducted to evaluate the effect of vaccination on age and sex (Table 2). All analyses were conducted using SAS software, Version 9.3 (SAS, Cary, NC, USA). A 2-tailed $P$ value of $<0.05$ was considered significant. In sensitivity analyses, external adjustments improve the understanding of the effects of drugs and other covariates in epidemiological database studies [23]. Hence, in the sensitivity analysis, we made adjustments to examine the association of age, sex, CCI, comorbidities, and drug use with the incidence of ischemic stroke in different models. The models stratified by different seasons were adjusted for covariates in the main model and each additional covariate (Tables 3-5).

\section{CONCLUSIONS}

Influenza vaccination might exert a dose-response effect against ischemic stroke in patients with AF who have risk factors for ischemic stroke by reducing the incidence of ischemic stroke, particularly in those aged $65-74$ and $\geq 75 \mathrm{y}$.

\section{Abbreviations}

AF, atrial fibrillation; NHI, National Health Insurance; NHIRD, National Health Insurance Research Database; ICD-9-CM, International Classification of Diseases, Ninth Revision, Clinical Modification; ACEI, angiotensin-converting enzyme inhibitor; PS, propensity score; HR, hazard ratio; AD, Alzheimer disease.

\section{Author contributions}

Dr. Szu-Yuan $\mathrm{Wu}^{*}$ and Dr. Ju-Chi Liu: Study concept and design

All authors: Data acquisition

Dr. Szu-Yuan $\mathrm{Wu}^{*}$ : Analysis and interpretation

Dr. Szu-Yuan $\mathrm{Wu}^{*}$ and Dr. Ju-Chi Liu: Critical revision of the manuscript for important intellectual content

Dr. Szu-Yuan $\mathrm{Wu}^{*}$ and Dr. Ju-Chi Liu: Study supervision

\section{ACKNOWLEDGMENTS}

All authors equally contributed to this research work

\section{CONFLICTS OF INTEREST}

The author(s) indicate that no potential conflicts of interest exist.

\author{
Employment or Leadership Position: None \\ Consultant or Advisory Role: None \\ Stock Ownership: None \\ Honoraria: None \\ Research Funding: Taipei Medical University \\ Expert Testimony: None \\ Patents: None \\ Other Remuneration: None \\ Funding: Taipei Medical University
}

\section{REFERENCES}

1. Wein TH, Bornstein NM. Stroke prevention: cardiac and carotid-related stroke. Neurol Clin. 2000; 18:321-41. https://doi.org/10.1016/S0733-8619(05)70195-X. 
2. Di Tullio MR, Homma S. Mechanisms of cardioembolic stroke. Curr Cardiol Rep. 2002; 4:141-48. https://doi. org/10.1007/s11886-002-0027-3.

3. Barnes ME, Miyasaka Y, Seward JB, Gersh BJ, Rosales AG, Bailey KR, Petty GW, Wiebers DO, Tsang TS. Left atrial volume in the prediction of first ischemic stroke in an elderly cohort without atrial fibrillation. Mayo Clin Proc. 2004; 79:1008-14. https://doi.org/10.4065/79.8.1008.

4. Anderson DC, Kappelle LJ, Eliasziw M, Babikian VL, Pearce LA, Barnett HJ, Blakely J. Occurrence of hemispheric and retinal ischemia in atrial fibrillation compared with carotid stenosis. Stroke. 2002; 33:1963-67. https://doi.org/10.1161/01.STR.0000023445.20454.A8.

5. Harrison MJ, Marshall J. Atrial fibrillation, TIAs and completed strokes. Stroke. 1984; 15:441-42. https://doi. org/10.1161/01.STR.15.3.441.

6. Hart RG, Pearce LA, Miller VT, Anderson DC, Rothrock JF, Albers GW, Nasco E. Cardioembolic vs. noncardioembolic strokes in atrial fibrillation: frequency and effect of antithrombotic agents in the stroke prevention in atrial fibrillation studies. Cerebrovasc Dis. 2000; 10:39-43. https://doi.org/10.1159/000016023.

7. Singer DE, Hughes RA, Gress DR, Sheehan MA, Oertel LB, Maraventano SW, Blewett DR, Rosner B, Kistler JP, and Boston Area Anticoagulation Trial for Atrial Fibrillation Investigators. The effect of low-dose warfarin on the risk of stroke in patients with nonrheumatic atrial fibrillation. N Engl J Med. 1990; 323:1505-11. https://doi.org/10.1056/ NEJM199011293232201.

8. Stroke Prevention in Atrial Fibrillation Investigators. Stroke Prevention in Atrial Fibrillation Study. Final results. Circulation. 1991; 84:527-39. https://doi.org/10.1161/01. CIR.84.2.527.

9. Stroke Prevention in Atrial Fibrillation Investigators. Warfarin versus aspirin for prevention of thromboembolism in atrial fibrillation: Stroke Prevention in Atrial Fibrillation II Study. Lancet. 1994; 343:687-91.

10. Ezekowitz MD, Bridgers SL, James KE, Carliner NH, Colling CL, Gornick CC, Krause-Steinrauf H, Kurtzke JF, Nazarian SM, Radford MJ, Rickles FR, Shabetai R, Deykin $\mathrm{D}$, and Veterans Affairs Stroke Prevention in Nonrheumatic Atrial Fibrillation Investigators. Warfarin in the prevention of stroke associated with nonrheumatic atrial fibrillation. N Engl J Med. 1992; 327:1406-12. https://doi.org/10.1056/ NEJM199211123272002.

11. Fang MC, Go AS, Chang Y, Hylek EM, Henault LE, Jensvold NG, Singer DE. Death and disability from warfarin-associated intracranial and extracranial hemorrhages. Am J Med. 2007; 120:700-05. https://doi. org/10.1016/j.amjmed.2006.07.034.

12. Gage BF, Waterman AD, Shannon W, Boechler M, Rich MW, Radford MJ. Validation of clinical classification schemes for predicting stroke: results from the National Registry of Atrial Fibrillation. JAMA. 2001; 285:2864-70. https://doi.org/10.1001/jama.285.22.2864.
13. Lavallée P, Perchaud V, Gautier-Bertrand M, Grabli D, Amarenco P. Association between influenza vaccination and reduced risk of brain infarction. Stroke. 2002; 33:513-18. https://doi.org/10.1161/hs0202.102328.

14. Nichol KL, Nordin J, Mullooly J, Lask R, Fillbrandt $\mathrm{K}$, Iwane $\mathrm{M}$. Influenza vaccination and reduction in hospitalizations for cardiac disease and stroke among the elderly. N Engl J Med. 2003; 348:1322-32. https://doi. org/10.1056/NEJMoa025028.

15. Issac TT, Dokainish H, Lakkis NM. Role of inflammation in initiation and perpetuation of atrial fibrillation: a systematic review of the published data. J Am Coll Cardiol. 2007; 50:2021-28. https://doi.org/10.1016/j.jacc.2007.06.054.

16. Guo Y, Lip GY, Apostolakis S. Inflammation in atrial fibrillation. J Am Coll Cardiol. 2012; 60:2263-70. https:// doi.org/10.1016/j.jacc.2012.04.063.

17. Chang TY, Chao TF, Liu CJ, Chen SJ, Chung FP, Liao JN, Tuan TC, Chen TJ, Chen SA. The association between influenza infection, vaccination, and atrial fibrillation: A nationwide case-control study. Heart Rhythm. 2016; 13:1189-94. https://doi.org/10.1016/j.hrthm.2016.01.026.

18. Chen CI, Kuan CF, Fang YA, Liu SH, Liu JC, Wu LL, Chang CJ, Yang HC, Hwang J, Miser JS, Wu SY. Cancer risk in HBV patients with statin and metformin use: a population-based cohort study. Medicine (Baltimore). 2015; 94:e462. https://doi.org/10.1097/MD.0000000000000462.

19. Hung IF, Leung AY, Chu DW, Leung D, Cheung T, Chan CK, Lam CL, Liu SH, Chu CM, Ho PL, Chan S, Lam TH, Liang R, Yuen KY. Prevention of acute myocardial infarction and stroke among elderly persons by dual pneumococcal and influenza vaccination: a prospective cohort study. Clin Infect Dis. 2010; 51:1007-16. https:// doi.org/10.1086/656587.

20. Liu JC, Hsu YP, Kao PF, Hao WR, Liu SH, Lin CF, Sung LC, Wu SY. Influenza Vaccination Reduces Dementia Risk in Chronic Kidney Disease Patients: A Population-Based Cohort Study. Medicine (Baltimore). 2016; 95:e2868. https://doi.org/10.1097/MD.0000000000002868.

21. Madjid M, Naghavi M, Litovsky S, Casscells SW. Influenza and cardiovascular disease: a new opportunity for prevention and the need for further studies. Circulation. 2003; 108:2730-36. https://doi.org/10.1161/01. CIR.0000102380.47012.92.

22. Madjid M, Aboshady I, Awan I, Litovsky S, Casscells SW. Influenza and cardiovascular disease: is there a causal relationship? Tex Heart Inst J. 2004; 31:4-13.

23. Naghavi M, Wyde P, Litovsky S, Madjid M, Akhtar A, Naguib S, Siadaty MS, Sanati S, Casscells W. Influenza infection exerts prominent inflammatory and thrombotic effects on the atherosclerotic plaques of apolipoprotein E-deficient mice. Circulation. 2003; 107:762-68. https:// doi.org/10.1161/01.CIR.0000048190.68071.2B.

24. Van Lenten BJ, Wagner AC, Nayak DP, Hama S, Navab M, Fogelman AM. High-density lipoprotein loses its 
anti-inflammatory properties during acute influenza a infection. Circulation. 2001; 103:2283-88. https://doi. org/10.1161/01.CIR.103.18.2283.

25. Hayden FG, Treanor JJ, Fritz RS, Lobo M, Betts RF, Miller M, Kinnersley N, Mills RG, Ward P, Straus SE. Use of the oral neuraminidase inhibitor oseltamivir in experimental human influenza: randomized controlled trials for prevention and treatment. JAMA. 1999; 282:1240-46. https://doi.org/10.1001/jama.282.13.1240.

26. Urbanek C, Palm F, Grau AJ. Influenza and stroke risk: a key target not to be missed? Infect Disord Drug Targets. 2010; 10:122-31. https://doi.org/10.2174/187152610790963474.

27. Smeeth L, Thomas SL, Hall AJ, Hubbard R, Farrington P, Vallance P. Risk of myocardial infarction and stroke after acute infection or vaccination. N Engl J Med. 2004; 351:2611-18. https://doi.org/10.1056/NEJMoa041747.

28. Lo YC, Chuang JH, Kuo HW, Huang WT, Hsu YF, Liu MT, Chen $\mathrm{CH}$, Huang HH, Chang CH, Chou JH, Chang FY, Lin TY, Chiu WT. Surveillance and vaccine effectiveness of an influenza epidemic predominated by vaccine-mismatched influenza B/Yamagata-lineage viruses in Taiwan, 2011-12 season. PLoS One. 2013; 8:e58222. https://doi.org/10.1371/ journal.pone.0058222.

29. Lan YC, Su MC, Chen CH, Huang SH, Chen WL, Tien $\mathrm{N}$, Lin CW. Epidemiology of pandemic influenza A/ H1N1 virus during 2009-2010 in Taiwan. Virus Res. 2013; 177:46-54. https://doi.org/10.1016/j.virusres.2013.07.007.

30. Chu TP, Li CC, Wang L, Hsu LW, Eng HL, You HL, Liu JW, Wei CC, Chang LS, Lee IK, Yang KD. A surveillance system to reduce transmission of pandemic H1N1 (2009) influenza in a 2600-bed medical center. PLoS One. 2012; 7:e32731. https://doi.org/10.1371/journal.pone.0032731.

31. Lamassa M, Di Carlo A, Pracucci G, Basile AM, Trefoloni G, Vanni P, Spolveri S, Baruffi MC, Landini G, Ghetti A, Wolfe CD, Inzitari D. Characteristics, outcome, and care of stroke associated with atrial fibrillation in Europe: data from a multicenter multinational hospital-based registry (The European Community Stroke Project). Stroke. 2001; 32:392-98. https://doi.org/10.1161/01.STR.32.2.392.

32. Jørgensen HS, Nakayama H, Reith J, Raaschou HO, Olsen TS. Acute stroke with atrial fibrillation. The Copenhagen Stroke Study. Stroke. 1996; 27:1765-69. https://doi. org/10.1161/01.STR.27.10.1765.

33. Lip GY, Nieuwlaat R, Pisters R, Lane DA, Crijns HJ. Refining clinical risk stratification for predicting stroke and thromboembolism in atrial fibrillation using a novel risk factor-based approach: the euro heart survey on atrial fibrillation. Chest. 2010; 137:263-72. https://doi. org/10.1378/chest.09-1584.

34. Yarmohammadi H, Varr BC, Puwanant S, Lieber E, Williams SJ, Klostermann T, Jasper SE, Whitman C, Klein AL. Role of CHADS2 score in evaluation of thromboembolic risk and mortality in patients with atrial fibrillation undergoing direct current cardioversion (from the ACUTE Trial Substudy). Am J Cardiol. 2012; 110:22226. https://doi.org/10.1016/j.amjcard.2012.03.017.

35. Morgenstern LB, Hemphill JC 3rd, Anderson C, Becker K, Broderick JP, Connolly ES Jr, Greenberg SM, Huang JN, MacDonald RL, Messé SR, Mitchell PH, Selim M, Tamargo RJ, and American Heart Association Stroke Council and Council on Cardiovascular Nursing. Guidelines for the management of spontaneous intracerebral hemorrhage: a guideline for healthcare professionals from the American Heart Association/American Stroke Association. Stroke. 2010; 41:2108-29. https://doi.org/10.1161/ STR.0b013e3181ec611b.

36. Arima H, Hart RG, Colman S, Chalmers J, Anderson C, Rodgers A, Woodward M, MacMahon S, Neal B, and PROGRESS Collaborative Group. Perindopril-based blood pressure-lowering reduces major vascular events in patients with atrial fibrillation and prior stroke or transient ischemic attack. Stroke. 2005; 36:2164-69. https://doi. org/10.1161/01.STR.0000181115.59173.42.

37. Ageno W, Gallus AS, Wittkowsky A, Crowther M, Hylek EM, Palareti G. Oral anticoagulant therapy: Antithrombotic Therapy and Prevention of Thrombosis, 9th ed: American College of Chest Physicians Evidence-Based Clinical Practice Guidelines. Chest. 2012 (Suppl); 141:e44S-88S. https://doi.org/10.1378/chest.11-2292.

38. Friberg L, Benson L, Rosenqvist M, Lip GY. Assessment of female sex as a risk factor in atrial fibrillation in Sweden: nationwide retrospective cohort study. BMJ. 2012; 344:e3522. https://doi.org/10.1136/bmj.e3522.

39. Crighton EJ, Elliott SJ, Moineddin R, Kanaroglou P, Upshur RE. An exploratory spatial analysis of pneumonia and influenza hospitalizations in Ontario by age and gender. Epidemiol Infect. 2007; 135:253-61. https://doi. org/10.1017/S095026880600690X.

40. Jensen-Fangel S, Mohey R, Johnsen SP, Andersen PL, Sørensen HT, Ostergaard L. Gender differences in hospitalization rates for respiratory tract infections in Danish youth. Scand J Infect Dis. 2004; 36:31-36. https:// doi.org/10.1080/00365540310017618.

41. Brinkhof MW, Spoerri A, Birrer A, Hagman R, Koch D, Zwahlen M. Influenza-attributable mortality among the elderly in Switzerland. Swiss Med Wkly. 2006; 136:302-09.

42. Centers for Disease Control and Prevention. 2010-2011 Influenza Season Surveillance. 2013.

43. Liu IF, Huang CC, Chan WL, Huang PH, Chung CM, Lin SJ, Chen JW, Leu HB. Effects of annual influenza vaccination on mortality and hospitalization in elderly patients with ischemic heart disease: a nationwide population-based study. Prev Med. 2012; 54:431-33. https://doi.org/10.1016/j.ypmed.2012.03.020.

44. Lau D, Eurich DT, Majumdar SR, Katz A, Johnson JA. Effectiveness of influenza vaccination in working-age 
adults with diabetes: a population-based cohort study. Thorax. 2013; 68:658-63. https://doi.org/10.1136/ thoraxjnl-2012-203109.

45. Dodds L, McNeil SA, Fell DB, Allen VM, Coombs A, Scott J, MacDonald N. Impact of influenza exposure on rates of hospital admissions and physician visits because of respiratory illness among pregnant women. CMAJ. 2007; 176:463-68. https://doi.org/10.1503/cmaj.061435.

46. Wei SH, Chiang CS, Chen CL, Chiu CH. Pneumococcal disease and use of pneumococcal vaccines in Taiwan. Clin Exp Vaccine Res. 2015; 4:121-29. https://doi.org/10.7774/ cevr.2015.4.2.121.

47. Chang YC, Chou YJ, Liu JY, Yeh TF, Huang N. Additive benefits of pneumococcal and influenza vaccines among elderly persons aged 75 years or older in Taiwan--a representative population-based comparative study. J Infect. 2012; 65:231-38. https://doi.org/10.1016/j.jinf.2012.04.014.

48. Hsieh CY, Chen CH, Li CY, Lai ML. Validating the diagnosis of acute ischemic stroke in a National Health Insurance claims database. J Formos Med Assoc. 2015; 114:254-59. https://doi.org/10.1016/j.jfma.2013.09.009.

49. Sung SF, Hsieh CY, Lin HJ, Chen YW, Yang YH, Li CY. Validation of algorithms to identify stroke risk factors in patients with acute ischemic stroke, transient ischemic attack, or intracerebral hemorrhage in an administrative claims database. Int J Cardiol. 2016; 215:277-82. https:// doi.org/10.1016/j.ijcard.2016.04.069. 